the late Mr. Critchett, which was attended with very satisfactory results to the patient and his doctors.

Mr. Carter thinks he has got rid of me "for evermore" by bringing an unfounded accusation of "absolute falsehood" against me, but he goes further, and seeks to exclude from the discussion all homocopathic practitioners by saying that "the question is not one for them but for us"-a sentiment which, methinks, will hardly be endorsed by you, with your excellent motto, audi alterum partem.

I think Mr. Carter makes a mistake in supposing that his beliefs and prejudices are the standard whereby the whole medical profession is to regulate its conduct towards those who differ from them on therapeutic matters; and he will hardly increase the estimation in which the profession is held by the public by his wholesale charges of "fraudulent" conduct and sordid motives.

I am, Sirs, yours obediently,

Seaview, Sept. 1st, 1890. R. E. DUDGHON.

\section{THE DIAZO REACTION.}

\section{To the Editors of THE LANCET.}

SIRs,-Noticing Dr. Knight's article in THE LANCET of Sept. 20th, regarding the value of the diazo reaction, I beg to state that a few weeks ago I found it very useful in helping to establish the diagnosis of enteric fever. The case was to all intents and purposes one of ordinary summer diarrhœa when I first saw it, there being no typical stools and no pain on pressure in the right iliac fossa, and only slight elevation of temperature. After checking the diarrhoea, I detected slight gurgling in the crecal region and a certain amount of tympanites, which made me suspect typhoid. I therefore had the following test solutions prepared :- Fifty cc. of hydrochloric acid made up to 1000 cc. with water, and sulphanilic acid added to saturation. To 200 cc. of this mixture 5 cc. of a $\frac{1}{2}$ per cent. solution of sodium nitrite were added, and the resulting fluid added to the urine in equal parts. In about three hours a decided crimson colour was developed. Thinking this delay in the production of the crimson colour was due to some defect in my test, or that it might result from the exposure to the air of the components of the test solution, I added some of the latter to an equal part of normal urine, as a control experiment, with the result that only a deeper yellow tinge was developed in the normal urine in about three or four hours. Shortly after making this test the patient showed further signs, of a less equivocal nature, of enteric fever, and such the case eventually turned out to be. I would very much like to know whether the delay in getting the characteristic crimson colour has been noticed by your correspondents, as in every test I made in the above case $I$ was unable to obtain the reaction until after the lapse of several hours after adding the test solution to the urine.

I am, Sirs, yours faithfully, George C. STEPheN, M.D., L.R.C.P., L.S.A.

Sutherland Avenue, W., Sept. 19th, 1890.

\section{INTUBATION OF THE LARYNX.}

\section{To the Editors of THE LANCET.}

SIRs,-Most of those who have employed intubation of the larynx complain of the difficulty of removing the tube, and as in order to do this it is necessary to find the very small aperture of the tube and to insert the tip of the extractor sufficiently but not too deeply into it, there can be no question that it is both difficult to do and dangerous if bungled from the blocking up of the air passage. May I ask whether it has occurred to anyone to use a powerful electro-magnet of suitable shape for this purpose-the tube of course being of iron-plated? I should think that the same instrument might serve for an introducer. If the aperture of the tube were to be between the poles of the horseshoe magnet, there would be no obstruction to the air while the tube was being dropped into the larynx, and when in its place the current could be broken aud the introducer removed, leaving the tube in situ.

I am, Sirs, yours truly,

THeOdoRe MAXWELL, M.D.

Woolwich-common, Sept. 22nd, 1890
NOTIFICATION: IS IT LIKELY TO SUCCEED?

To the Editors of The LANCET.

SIRs,--If there is one thing more than another which would be likely to bring about a cry for the repeal of the Notification $\Lambda$ cts, it is the inclusion of whooping-cough and measles in the list of notifiable diseases, both on account of the expense connected therewith and the small result likely to be obtained therefrom. In the early stages neither of these diseases is easily recognisable, at any rate by untrained persons, while the capability of reproducing the disease ls undoubtedly present. As an instance of this I will cite the following two cases. At a large children's party one child appeared with one or two spots on the forehead, but nothing was thought of the matter till one child after another fell ill with the measles, and within one month nearly every child that had been present at this party was laid up. On another occasion one child came to a party with a slight cough, and as a result several who were present fell sick with whooping. cough of a very severe type, and two or more nearly succumbed. Of course, there is great risk of infection from mild unrecognised cases of diphtheria, enteric and scarlet fevers, but the deaths from these diseases is not so great as they are from the first two mentioned. The causes of the first are unknown, while those of the latter are well recognised, and to do away with or even permanently lessen infectious disease we must do away with the causes.

I am, Sirs, yours obediently,

Surbiton, Sept. 22nd, 1890.

F. P. ATKInson.

\section{BIRMINGHAM.}

(From our own CoRrespondent.)

Scarlet Fcver.

THE prevalence of this disease continues unabated; indeed, a slight increase has lately taken place in the number of cases. The Health Committee are considering the advisability of providing another ward in the City Hospital, and though practically almost all the cases are treated in the hospital, there is great difficulty in keeping pace with the number of fresh cases which are constantly occurring.

Queen's College.

The conversazione fixed for Oct. lst is looked forward to with much interest. The enthusiasm is largely due to the fact that Sir William Turner has promised to be present to distribute the prizes, and also to the spirit which has lately grown up in the arrangement of the College. Old things have passed away, and traditions have been ignored in the administration of the medical department. The result has been additional convenience and comfort all round both to teachers and students, with every prospect of rapid and substantial growth in the status of the College.

\section{Drink Doikinant.}

Of 61 cases entered at the Police-court on the 22nd inst. 31 were charges of drunkenness, with its concomitants. Of this number 23 were men and 8 were women. One woman aged twenty-six had been 48 times before the Court; another woman aged eighty had been 36 times in custody. Of the total number of drunkards 15 were under thirty years of age. Evidently the best governed city in the world has yet a large task before it in the cultivation of good manners, and the removal of such a hideous blot upon its civilisation.

Charges against the Health Committee.

In reference to the complaints of maladministration a gainst this committee connected with the interception department, after a full and patient investigation, it has been shown that there has not been sufficient proof of incompetency or neglect as formulated. The failure has yet to be reported to the council, but there is every reason to believe that the confidence previously existing in the committee will be unshaken, and that, as a body of hard-working citizens devoting a large amount of time to the public good, they will be accredited with unsullied motives in the discharge of their duties.

Birmingham, Sept. 24 th. 